\title{
Improving shear bond strength of temporary crown and fixed dental prosthesis resins by surface treatments
}

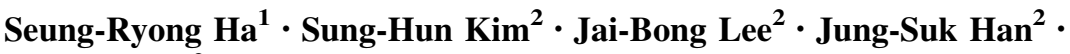 \\ In-Sung Yeo ${ }^{2}$
}

Received: 25 August 2015/Accepted: 26 September 2015/Published online: 5 October 2015

(C) The Author(s) 2015. This article is published with open access at Springerlink.com

\begin{abstract}
This study evaluated the effect of surface treatments on the bond strength of repaired temporary resins. One-hundred flat-surfaced cylindrical specimens $(\varnothing$ $7 \mathrm{~mm} \times 12 \mathrm{~mm}$ ) of each temporary resin (2 bis-acryl resins and 2 polymethyl-methacrylates) were prepared. The specimens were randomly divided into 10 groups $(n=10)$, according to the types of surface treatments: untreated, adhesive treated, silanated, silane + adhesive treated, hydrofluoric acid etched, laser treated, sandblasted, sandblasting + adhesive treated, sandblasting + silanated, and tribochemical silica coating + silanated. Each resin material of the same brand with cylindrical shape ( $\varnothing$ $3 \mathrm{~mm} \times 3 \mathrm{~mm}$ ) was polymerized onto the resin surfaces, and specimens were stored for $24 \mathrm{~h}$ in distilled water. The shear bond strengths were measured and failure modes were examined. All data were analyzed with a one-way ANOVA and multiple comparison Scheffé post hoc test $(\alpha=0.05)$. For bis-acryl resins, the highest shear bond strength was observed in sandblasted group and the lowest was observed in the control group. Results show that the repair bond strength was improved for bis-acryl resin by $23 \%$ than that of the control group due to the increase in surface roughness by sandblasting. However, chemical treatment did not improve repair bond strength. The surface treatment of bis-acryl resins with sandblasting seems to be promising for the improvement of repair bond strength.
\end{abstract}

Sung-Hun Kim

ksh1250@snu.ac.kr

1 Department of Dentistry, Ajou University School of Medicine, Suwon, Republic of Korea

2 Department of Prosthodontics and Dental Research Institute, School of Dentistry, Seoul National University, Seoul, Republic of Korea

\section{Introduction}

Temporary crowns and fixed dental prostheses (FDPs) are often required to provide long-term stability and tooth protection while complementary treatments are provided [1]. The long-term maintenance of the temporary restorations with procedures such as endodontic therapy, orthodontics, chemotherapy, tissue grafting, and implant surgery is frequently useful [1]. The temporary restorations must meet not only esthetic and biologic needs, but also mechanical needs such as resistance to dislodging forces and functional loads [2]. However, complications, such as fractures, could occur with more extensive temporary restorations that are intended for long-term uses. The restorations are subject to various forces in oral conditions: compressive force at the load application; and tensile and shear force at the load resistance [3]. Fracture of a longspan temporary restoration is more likely to happen compared to a short-span restoration because the fracture resistance is inversely proportional to the cube of the restoration length. Fracture of the temporary restorations could cause economic loss and discomfort to both clinicians and patients [4].

In clinical practice, most repairs of temporary restorations are accomplished using an auto-polymerizing resin of the same brand that was used in original temporary restorations. A durable repairing system for the fractured temporary restorations is desired to avoid frequent fracture. Attempts to improve bond strength of restorative materials involve mechanical and chemical means. Many methods have been introduced for modification of a filling composite resin surface: sandblasting, roughening with diamond instrument, abrasive papers, and acid etching [5-7]. Several studies have demonstrated that the application of 
chemical agent, such as bonding agent or silane coupling agent, enhances the bond strength [6-11].

Koumjian and Nimmo [12] reported that transverse strength was reduced by $85 \%$ after repair of a temporary resin. Their study proposed that it might be more convenient to prepare a new temporary restoration than to repair the restoration. However, repair of the fractured temporary restoration could be cost- and time-efficient treatment option in clinical situations. For a successful repair, bond strength comparable to the strength of the original material is required. Therefore, it is important to measure the repair bond strengths of various surface treatments on the temporary restorations. However, there have been only few studies on the effect of surface treatments on the repair bond strength of the temporary crown and FDP materials [13-15].

The present study was conducted to determine the effect of different surface treatments on the shear bond strength of the temporary crown and FDP materials. The null hypothesis to be tested was that there is no difference in shear bond strength among various surface treatments on the repaired temporary crown and FDP materials.

\section{Materials and methods}

\section{Preparation of the specimens}

The materials investigated in the present study were 2 bisacryl resins and 2 auto-polymerizing polymethyl methacrylate (PMMA) resins (Table 1). The bis-acryl resin was dispensed from a cartridge in a dispensing gun through a mixing tip. A small amount of the resin was extruded and discarded, and then the resin was placed into a customized polytetrafluoroethylene (PTFE) mold of $7 \mathrm{~mm}$ inner diameter and $12 \mathrm{~mm}$ height (Fig. 1a). The PMMA resins were mixed according to the manufacturers' instructions. The PMMA powder was saturated and mixed with liquid monomer, using a metal spatula for $20 \mathrm{~s}$ and immediately placed into the PTFE mold. A vinyl strip and a glass plate were located onto the mold to form flat end surfaces, and hand pressure was applied to extrude excess material. The specimens were allowed to polymerize for $60 \mathrm{~min}$ at $23 \pm 1{ }^{\circ} \mathrm{C}$. Four-hundred specimens were fabricated (100 specimens for each material).

\section{Surface treatment of specimens}

The specimens were randomly assigned to one of the ten groups ( $n=10$ for each group). Groups of specimens with the abbreviations and the preparation methods are presented in Table 2. Each specimen was modified by various surface treatments as follows:

- Group 1 (CON): No surface treatment.

- Group 2 (ADH): Adhesive monomer (Adper Scotchbond Multi-Purpose adhesive, Lot No. 6PN, 3M ESPE, St. Paul, MN, USA) was applied twice, thinned with oil-free compressed air, and then cured for $20 \mathrm{~s}$ using a quartz halogen curing light (Elipar Trilight, 3M ESPE, Seefeld, Germany). The light intensity of the lamp was measured regularly with a radiation meter and maintained at the same level for all tests.

- Group 3 (SIL): Silane coupling agent (Porcelain primer, Lot No. 0700000153, Bisco, Schaumberg, IL, USA) was applied as a single coat and was allowed to dry for $5 \mathrm{~min}$.

- Group 4 (SI/A): Silane coupling agent was applied under the same conditions as above. Any residual solvent was evaporated with oil-free compressed air for $10 \mathrm{~s}$. Then, adhesive monomer was applied under the same conditions as in Group 2.

Table 1 Materials, manufacturers, lot numbers, and main compositions of the temporary crown and FDP materials investigated in this study

\begin{tabular}{|c|c|c|c|c|}
\hline Material & Manufacturer & Lot No. & Composition & Characteristics \\
\hline $\begin{array}{l}\text { Protemp } 3 \\
\text { Garant }\end{array}$ & 3M ESPE, Seefeld, Germany & $\begin{array}{l}\text { B } 319023 \\
\text { C } 318795\end{array}$ & DMA, SA, strontium glass & Bis-acryl composite resin \\
\hline Luxatemp & DMG, Hamburg, Germany & 513917 & $\begin{array}{l}\text { DMA, UDMA, GMA, silica, glass } \\
\text { powder }\end{array}$ & \\
\hline Vertex & $\begin{array}{l}\text { Vertex-Dental/Dentimex, Zeist, } \\
\text { Netherlands }\end{array}$ & $\begin{array}{l}\text { YR493L10 } \\
\text { YR274P02 }\end{array}$ & $\begin{array}{l}\text { MMA, cross-linker, accelerator, } \\
\text { polymer }\end{array}$ & $\begin{array}{l}\text { Polymethyl methacrylate } \\
\text { resin }\end{array}$ \\
\hline Jet & Lang, IL, USA & $\begin{array}{l}\text { 14425075/ } \\
01 \mathrm{AC} \\
6000906 \mathrm{AI} / \\
02 \mathrm{AB}\end{array}$ & MMA, DMT, DEP, polymer & \\
\hline
\end{tabular}

DMA dimethacrylate, $S A$ silicic acid, UDMA urethane dimethacrylate, GMA glycol methacrylate, $M M A$ methyl methacrylate, $D M T N, N$ dimethyl-p-toluidine, $D E P$ diethyl phthalate 
Fig. 1 Polytetrafluoroethylene mold used in this study: a for preparation of the specimens; b for repair
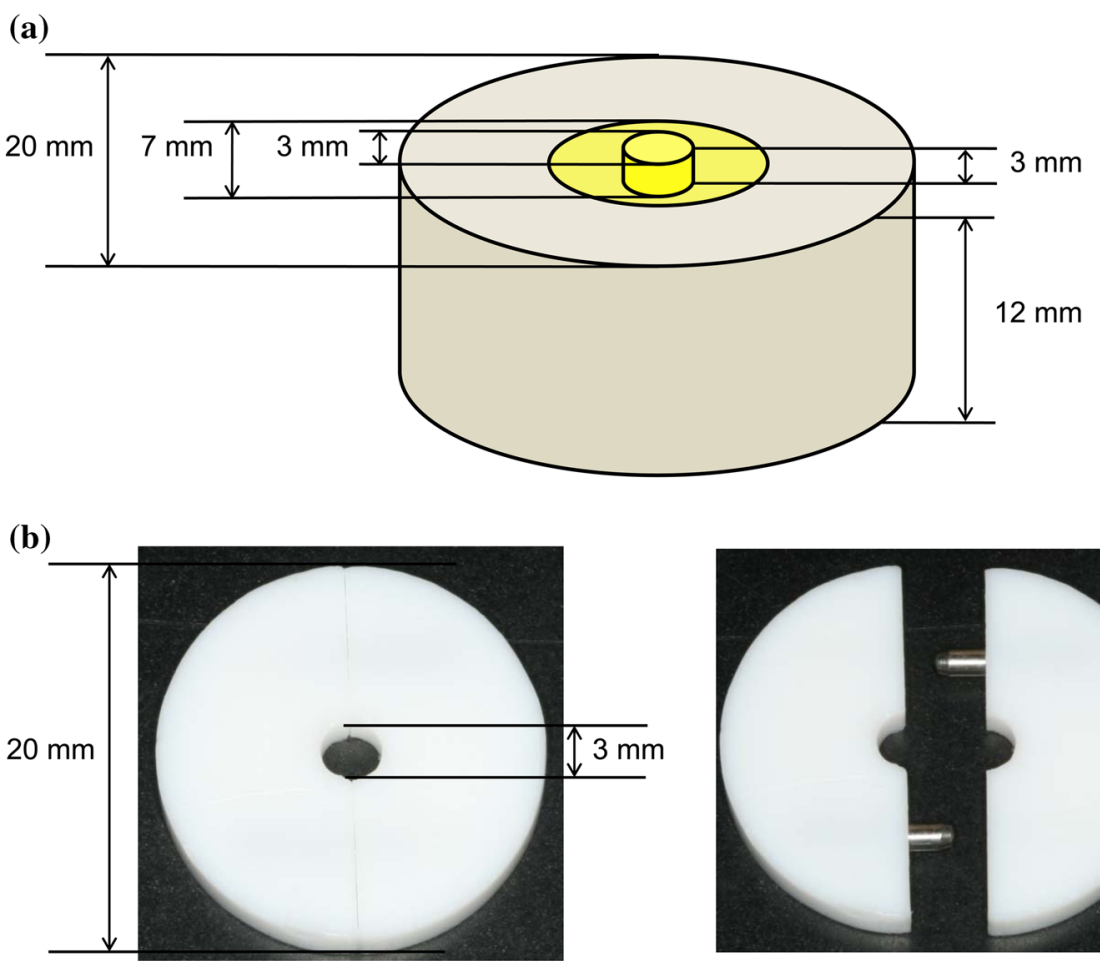

Table 2 Test groups for repairing temporary crown and FDP materials

\begin{tabular}{llll}
\hline $\begin{array}{l}\text { Group } \\
\text { abbreviation }\end{array}$ & Surface treatment & Mechanical treatment & Chemical treatment \\
\hline $\mathrm{CON}$ & Control & None & None \\
$\mathrm{ADH}$ & Adhesive & None & Unfilled bis-GMA resin application \\
$\mathrm{SIL}$ & Silane & None & Silane application \\
$\mathrm{SI} / \mathrm{A}$ & Silane + adhesive & None & Silane application, followed by unfilled bis-GMA \\
& & & resin application \\
$\mathrm{HFA}$ & Hydrofluoric acid & Etching with $4 \%$ hydrofluoric acid & None \\
$\mathrm{LAS}$ & Laser & Roughening with Er,Cr:YSGG laser & None \\
$\mathrm{SAN}$ & Sandblasting & Sandblasting with $50 \mu \mathrm{m} \mathrm{Al} \mathrm{O}_{3}$ particles & None \\
$\mathrm{SA} / \mathrm{A}$ & Sandblasting + adhesive & Sandblasting with $50 \mu \mathrm{m} \mathrm{Al}_{2} \mathrm{O}_{3}$ particles & Unfilled bis-GMA resin application \\
SA/S & Sandblasting + silane & Sandblasting with $50 \mu \mathrm{m} \mathrm{Al}_{2} \mathrm{O}_{3}$ particles & Silane application \\
TS/S & Tribochemical silica & Tribochemical silica coating with $30 \mu \mathrm{m}$ & Silane application \\
& coating + silane & silicatized sand & \\
\hline
\end{tabular}

$C O N$ control, $A D H$ adhesive, GMA glycol methacrylate, SIL silane, SI/A silane + adhesive, $H F A$ hydrofluoric acid, $L A S$ laser, $E r$ erbium, $C r$ chromium, YSGG yttrium-scandium-gallium-garnet, $S A N$ sandblasting, $S A / A$ sandblasting + adhesive, $S A / S$ sandblasting + silane, TS/S tribochemical silica coating + silane

- Group 5 (HFA): A thin layer of $4 \%$ hydrofluoric acid gel (Porcelain etchant, Lot No. 0600000878, Bisco) was applied for $120 \mathrm{~s}$. The specimen was rinsed with water for $120 \mathrm{~s}$ and dried with oil-free compressed air for $10 \mathrm{~s}$.

- Group 6 (LAS): The specimen was irradiated with the Er,Cr:YSGG laser (Waterlase MD, Lot No. 6200218, Biolase technology, San Clemente, CA, USA) under water cooling (30\% water, $30 \%$ air) at $2.25 \mathrm{~W}, 30 \mathrm{~Hz}$.
The optic fiber was used in a non-contact mode, in back and forth motions to assure a controlled irradiation of the surface. The specimen was rinsed with water for $20 \mathrm{~s}$ and dried with oil-free compressed air for $10 \mathrm{~s}$.

- Group 7 (SAN): Sandblasting with $50 \mu \mathrm{m}$ aluminum oxide $\left(\mathrm{Al}_{2} \mathrm{O}_{3}\right)$ particles was applied using an airborneparticle abrasion device (S-U-PROGRESA 200, Schuler-Dental, Germany) from a distance of approximately $10 \mathrm{~mm}$ at a pressure of 2 bar for $10 \mathrm{~s}$. The specimen 
was rinsed with water for $20 \mathrm{~s}$ and dried with oil-free compressed air for $10 \mathrm{~s}$.

- Group 8 (SA/A): Sandblasting process was applied using the same device under the same conditions as above. Then, adhesive monomer was applied under the same conditions as in Group 2.

- Group 9 (SA/S): Sandblasting was done under the same conditions as in Group 7. Then, silane coupling agent was applied under the same conditions as in Group 3.

- Group 10 (TS/S): Tribochemical silica coating was achieved using an intraoral blaster (3M ESPE, St. Paul, MN, USA) from a distance of approximately $10 \mathrm{~mm}$ with $30 \mu \mathrm{m}$ silicatized sand (Rocatec ${ }^{\mathrm{TM}}$-Soft, 3M ESPE) for $10 \mathrm{~s}$. The specimen was rinsed with water for $20 \mathrm{~s}$ and dried with oil-free compressed air for $10 \mathrm{~s}$. Then, silane coupling agent was applied under the same conditions as above.

\section{Scanning electron microscope examination}

Additional specimens of each resin were prepared for examination with a scanning electron microscope (SEM). Each specimen modified by mechanical treatment was examined using the SEM (FE-SEM, S-4700, Hitachi, Tokyo, Japan) at $\times 500$ and $\times 2000$ magnification to observe the topographic patterns.

\section{Repair of the specimens}

A PTFE mold with an opening of $3 \mathrm{~mm}$ diameter and $3 \mathrm{~mm}$ height was used for the repair of the specimens (Fig. 1b). The mold was positioned on the modified surface of each specimen, and its opening was filled with each fresh resin of the same brand to complete the repair procedure. The specimen was allowed to polymerize for $60 \mathrm{~min}$ at $23 \pm 1{ }^{\circ} \mathrm{C}$, and then the PTFE mold was gently removed from the specimen. The tested specimens received an identification number and were stored individually in distilled water at $37{ }^{\circ} \mathrm{C}$ for $24 \mathrm{~h}$ before mechanical testing.

\section{Shear bond strength test}

All specimens were moved from the storage container directly onto the testing apparatus. The specimens were inserted into a shear test jig, and the jig was secured in a universal testing machine (Instron, Model 3345, Instron, Canton, MA, USA). Then, shear load was applied to the adjacent bonding interface with a crosshead speed of $0.5 \mathrm{~mm} /$ min until fracture occurred using knife-edge rod (Fig. 2). Tests were carried out at the temperature of $23 \pm 1{ }^{\circ} \mathrm{C}$.

The bond strength values were calculated using the formula:
$\sigma=L / A$

where $\sigma$ is the bond strength (in MPa), $L$ is the load at failure (in $\mathrm{N}$ ), and $A$ is the repaired area (in $\mathrm{mm}^{2}$ ).

\section{Failure mode analysis}

The interfacial fractured surfaces of each test group were examined using a stereoscopic microscope $(\times 45$, Meiji 2000, Meiji Techno, Saitama, Japan). The specimens were classified according to fracture patterns: adhesive failure, mixed failure (combination of cohesive and adhesive failure), and cohesive failure.

\section{Statistical analysis}

Statistical analysis was performed by a one-way ANOVA and multiple comparison Scheffé post hoc tests with the statistical software (SPSS 22, SPSS Inc., Chicago, IL, USA). The test was performed at a significance level of 0.05 .

\section{Results}

The mean shear bond strength values and standard deviations of all groups are demonstrated in Table 3. The results of one-way ANOVA are presented in Tables 4, 5, 6, and 7.

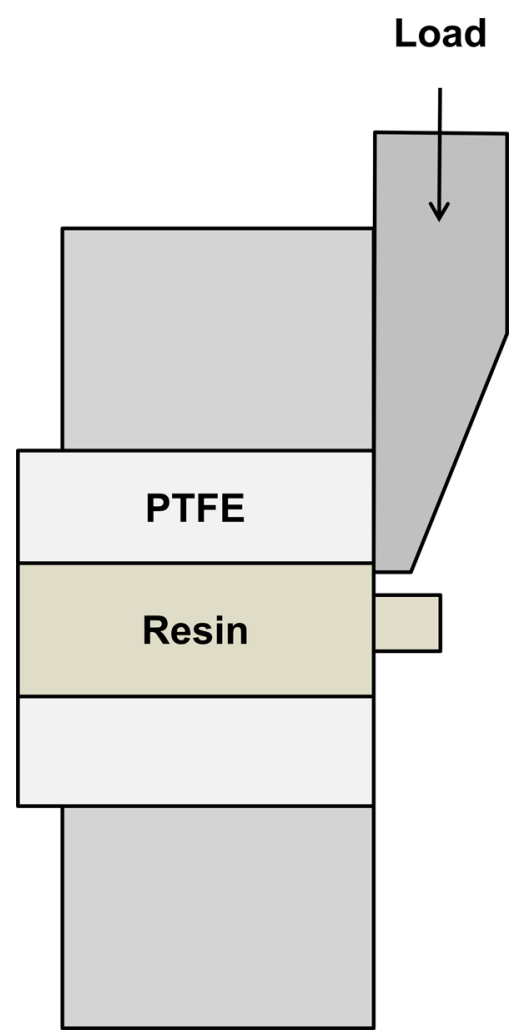

Fig. 2 Schematic diagram of shear bond test jig 


\section{Bis-acryl resin}

For Protemp 3 Garant, mean shear bond strength values ranged from 32.4 to $39.2 \mathrm{MPa}$. Group SAN obtained the highest mean shear bond strength with the value of 39.2 $\mathrm{MPa}$, followed by Group SA/A with the value of 35.9 MPa. These two methods did not differ significantly. On the other hand, Group CON exhibited the lowest value with the mean value of $32.4 \mathrm{MPa}$. The mean shear bond strength was $21 \%$ higher in the Group SAN than in the Group CON $(P<0.05$, Scheffé test $)$.

For Luxatemp, mean shear bond strength values ranged from 29.1 to $35.8 \mathrm{MPa}$. Group SAN revealed the highest mean shear bond strength with the value of $35.8 \mathrm{MPa}$, but Group CON showed the lowest with the value of 29.1 MPa. Although there was no significant difference in the mean shear bond strengths among the groups, it is noted that the Group SAN showed $23 \%$ higher value, on average, than the Group CON.

\section{Polymethyl methacrylate}

For Vertex, mean shear bond strength values ranged from 25.7 to $29.5 \mathrm{MPa}$. Group ADH had the highest mean shear bond strength value and Group SA/S had the lowest. The shear bond strength of the Group ADH was significantly higher than those of the Groups SA/S, CON, and LAS $(P<0.05$, Scheffé test $)$.

For Jet, mean shear bond strength values ranged from 22.8 to $26.8 \mathrm{MPa}$. As displayed in Table 7 , the mean shear bond strengths differed significantly among groups ( $P=0.000$, one-way ANOVA). Group SIL showed significantly higher mean shear bond strength value when compared to the Groups LAS, SA/A, or TS/S $(P<0.05$,
Table 4 Statistical analysis of shear bond strength of Protemp 3 Garant

\begin{tabular}{lcrlll}
\hline & Sum of squares & df & Mean square & $F$ & $P$ \\
\hline Treatment & 307.20 & 9 & 34.13 & 2.76 & 0.007 \\
Error & 1114.84 & 90 & 12.39 & & \\
Total & 1422.03 & 99 & & & \\
\hline
\end{tabular}

Table 5 Statistical analysis of shear bond strength of Luxatemp

\begin{tabular}{lcrlll}
\hline & Sum of squares & df & Mean square & $F$ & $P$ \\
\hline Treatment & 286.82 & 9 & 31.87 & 2.23 & 0.027 \\
Error & 1288.78 & 90 & 14.32 & & \\
Total & 1575.60 & 99 & & & \\
\hline
\end{tabular}

Table 6 Statistical analysis of shear bond strength of Vertex

\begin{tabular}{lcrcll}
\hline & Sum of squares & df & Mean square & $F$ & $P$ \\
\hline Treatment & 98.99 & 9 & 11.00 & 3.70 & 0.001 \\
Error & 267.33 & 90 & 2.97 & & \\
Total & 366.32 & 99 & & & \\
\hline
\end{tabular}

Scheffé test). In addition, a significant difference was noted between Groups ADH and LAS. However, when compared to Group CON, there was no statistical difference in mean shear bond strength values.

\section{Surface morphology}

SEM images showed that the topographic patterns differed among the specimens of which were etched with
Table 3 Mean shear bond strength (MPa) with standard deviations in parenthesis of temporary crown and FDP materials

\begin{tabular}{lllll}
\hline Group abbreviation & Protemp 3 Garant & Luxatemp & Vertex & Jet \\
\hline CON & $32.4(2.1)^{\mathrm{b}}$ & $29.1(2.0)^{\mathrm{c}}$ & $25.9(1.8)^{\mathrm{e}}$ & $25.0(2.0)^{\mathrm{f}, \mathrm{g}, \mathrm{h}}$ \\
ADH & $34.8(3.2)^{\mathrm{a}, \mathrm{b}}$ & $32.9(2.2)^{\mathrm{c}}$ & $29.5(2.5)^{\mathrm{d}}$ & $26.1(2.2)^{\mathrm{f}, \mathrm{g}}$ \\
SIL & $35.6(2.7)^{\mathrm{a}, \mathrm{b}}$ & $31.6(3.2)^{\mathrm{c}}$ & $26.6(1.6)^{\mathrm{d}, \mathrm{e}}$ & $26.8(1.9)^{\mathrm{f}}$ \\
SI/A & $33.6(4.2)^{\mathrm{a}, \mathrm{b}}$ & $31.3(4.5)^{\mathrm{c}}$ & $26.4(1.8)^{\mathrm{d}, \mathrm{e}}$ & $24.0(1.5)^{\mathrm{f}, \mathrm{g}, \mathrm{h}}$ \\
HFA & $34.0(7.2)^{\mathrm{a}, \mathrm{b}}$ & $34.2(5.9)^{\mathrm{c}}$ & $27.2(1.9)^{\mathrm{d}, \mathrm{e}}$ & $24.1(1.0)^{\mathrm{f}, \mathrm{g}, \mathrm{h}}$ \\
LAS & $33.7(2.5)^{\mathrm{a}, \mathrm{b}}$ & $31.7(3.9)^{\mathrm{c}}$ & $26.1(1.9)^{\mathrm{e}}$ & $22.8(2.1)^{\mathrm{h}}$ \\
SAN & $39.2(1.9)^{\mathrm{a}}$ & $35.8(3.4)^{\mathrm{c}}$ & $26.5(1.0)^{\mathrm{d}, \mathrm{e}}$ & $24.6(1.6)^{\mathrm{f}, \mathrm{g}, \mathrm{h}}$ \\
SA/A & $35.9(3.5)^{\mathrm{a}, \mathrm{b}}$ & $32.3(3.9)^{\mathrm{c}}$ & $26.7(2.0)^{\mathrm{d}, \mathrm{e}}$ & $23.6(1.3)^{\mathrm{g}, \mathrm{h}}$ \\
SA/S & $34.7(2.5)^{\mathrm{a}, \mathrm{b}}$ & $33.0(3.8)^{\mathrm{c}}$ & $25.7(1.1)^{\mathrm{e}}$ & $23.8(1.0)^{\mathrm{f}, \mathrm{g}, \mathrm{h}}$ \\
TS/S & $34.0(2.2)^{\mathrm{a}, \mathrm{b}}$ & $32.7(3.7)^{\mathrm{c}}$ & $26.5(1.2)^{\mathrm{d}, \mathrm{e}}$ & $23.6(1.1)^{\mathrm{g}, \mathrm{h}}$ \\
\hline Protem & $G$ & &
\end{tabular}

Protemp 3 Garant, Luxatemp, Vertex, and Jet data are analyzed separately

CON control, ADH adhesive, SIL silane, SI/A silane + adhesive, HFA hydrofluoric acid, LAS laser, SAN sandblasting, $S A / A$ sandblasting + adhesive, $S A / S$ sandblasting + silane, $T S / S$ tribochemical silica coating + silane

Same superscripted lowercase letters in each temporary crown and FDP material indicate no significant differences (Scheffé test: $P>0.05$ ) 
Table 7 Statistical analysis of shear bond strength of Jet

\begin{tabular}{llrcll}
\hline & Sum of squares & df & Mean square & $F$ & $P$ \\
\hline Treatment & 134.07 & 9 & 14.90 & 5.74 & 0.000 \\
Error & 233.70 & 90 & 2.60 & & \\
Total & 367.77 & 99 & & & \\
\hline
\end{tabular}

hydrofluoric acid, roughened with the Er,Cr:YSGG laser, or abraded with airborne $\mathrm{Al}_{2} \mathrm{O}_{3}$ particles (Figs. 3, 4, 5, 6). The surfaces of untreated specimens appeared relatively smooth (Figs. 3a, 4a, 5a, 6a and 3b, 4b, 5b, 6b). Hydrofluoric acid gel dissolved the fillers of the bis-acryl resins and produced porous irregular surfaces (Figs. 3d, 4d). However, SEM image of the PMMA resin surface treated with hydrofluoric acid showed no substantial difference from that of the untreated control group (Figs. 5d, 6d). The appearance of laser-treated specimen was very different from that of untreated specimen. Microcracks, fissures, grooves, and concavities were present on the surface of laser-treated specimen (Figs. 3f, 4f, 5f, 6f). SEM images of the sandblasted surfaces showed a micromechanical retention system and demonstrated visible changes in the topographic pattern. Their surface roughness was significantly increased (Figs. 3h, 4h, 5h, 6h).

\section{Failure mode}

Figure 7 presents the failure mode for all groups in the present study. Predominantly, cohesive failures were found in all groups of each resin. The cohesive failures were observed in each repaired resin, not repairing resin.

\section{Discussion}

As revealed by one-way ANOVA on the testing results of each material, the shear bond strengths of the temporary crown and FDP materials were affected by various surface treatments. Thus, the null hypothesis that there is no difference in shear bond strength among various surface treatments on the repaired temporary crown and FDP materials should be rejected. Adequate surface treatments should be carefully selected and utilized for each temporary restoration system due to the differences in chemical compositions of the temporary crown and FDP materials. For selection of the optimal surface treatment for every clinical situation, it is critical to know the bond strengths resulted from different surface treatments.

The results of the current study showed that sandblasting alone significantly increased the shear bond strength of the bis-acryl temporary crown and FDP materials. The effect of sandblasting may be attributed to an increase in the micromechanical retention that elevates the capability of the added bis-acryl resin to interlock mechanically onto the old resin. These results are in close agreement with many investigations reporting improved bond strengths when the filling composite resin was sandblasted before repair $[5,7$, $9,11]$. The findings of the current study demonstrate the importance of sandblasting and micromechanical retention in the bis-acryl temporary resin repair. Some studies have also shown that micromechanical retention is the most significant factor in the filling composite resin repair $[5,16$, 17]. However, some investigations have reported the reduced repair bond strength after sandblasting in the filling composite resin repair [18-20]. Possible causes of these reductions in bond strength are supposed in several studies. Surface debris or air inclusion on the repair site, exposure of filler components following sandblasting, and viscosity of filling composite resin can be all attributed to the reduction in bond strength [21].

The laser system used in the current study was Er,Cr:YSGG laser. This produces water vapor which increases pressure until a thermally induced mechanical ablation occurs $[22,23]$. In the current study, laser treatment led to the formation of microcracks, fissures, grooves, and concavities. Although the surface of laser-treated specimen in the SEM images was rougher than that of the control group, laser treatment did not result in the increase of bond strength compared to the control group. The roughened surface containing cliffs, microcracks, and other destructive topographic pattern may affect the results. Moreover, the presence of smear layer or surface debris following laser treatment could reduce the bond strength in each resin. This may suppose that the surface roughness is not a single critical factor contributing to the repair bond strength.

It has been reported that strong acid might dissolve filler on the filling composite resin surface, leaving gaps or pores, and create surface irregularities that allow micromechanical retention [24, 25]. This effect of strong acid is dependent on the type, percentage, and size of the filler [24]. However, some studies have reported that etching with hydrofluoric acid did not increase the adhesion of resin to some filling composite resins [25, 26]. In a study by Kula et al. [27], immersion of the filling composite resin in acidic medium decomposed the inorganic filler particles, resulting in impaired adhesion between composite layers. Swift et al. [24] investigated the dissolution of the filler and softening of the resin after etching of the composites with a $9.6 \%$ hydrofluoric acid for shorter duration. The study showed either decreased or increased bond strength, depending on the kind of filling composite resin being repaired [24]. The results of the present study showed that the application of hydrofluoric acid did not significantly improve the bond strength. This finding could 
(a)

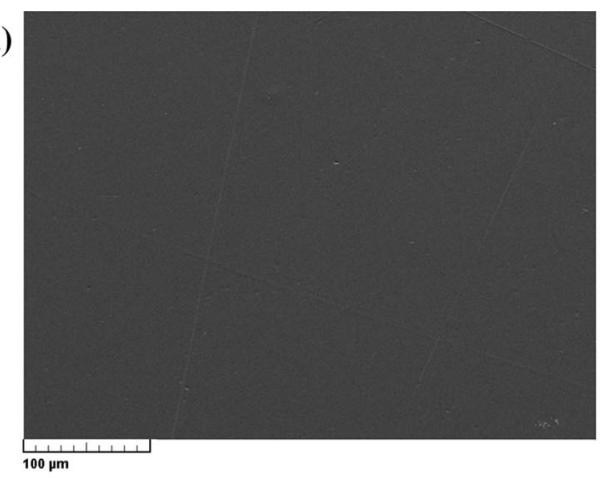

(c)

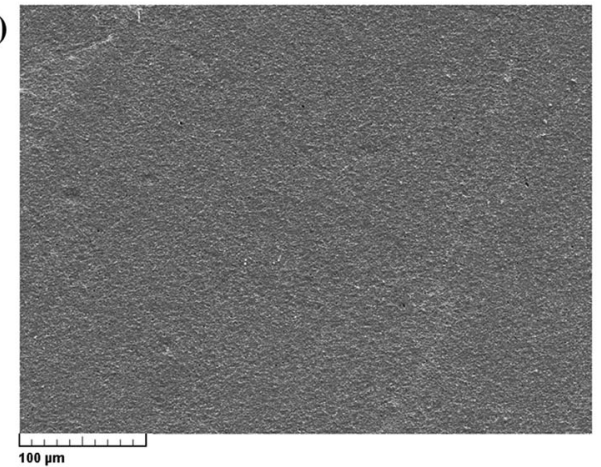

(e)

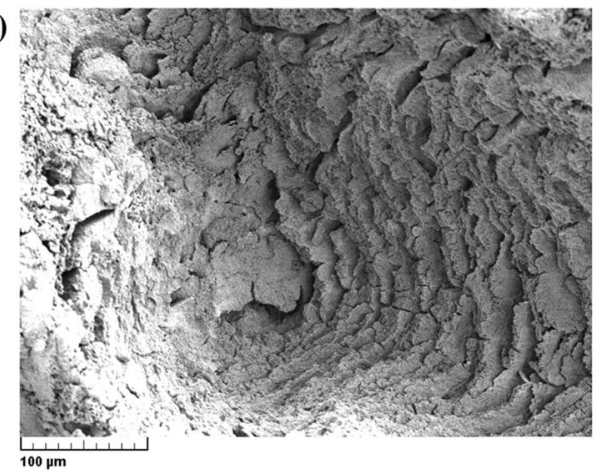

(g)

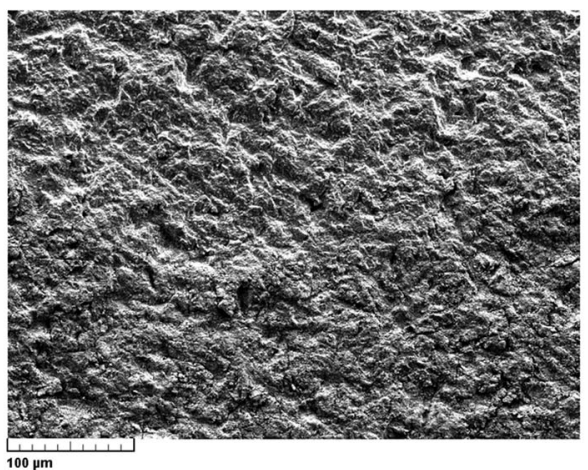

(b)

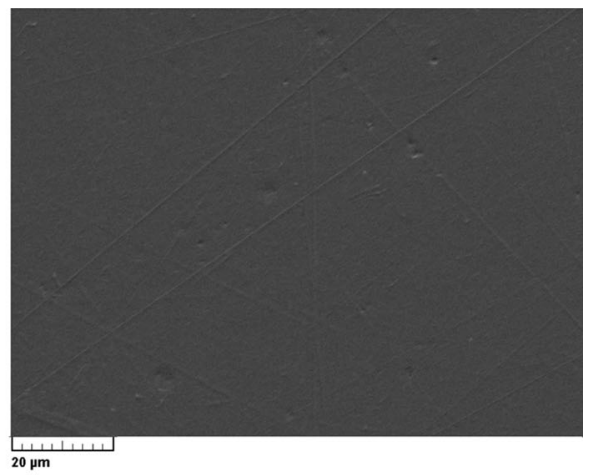

(d)

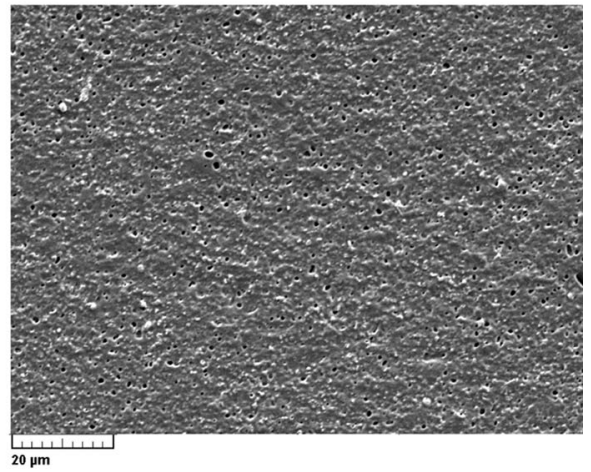

(f)

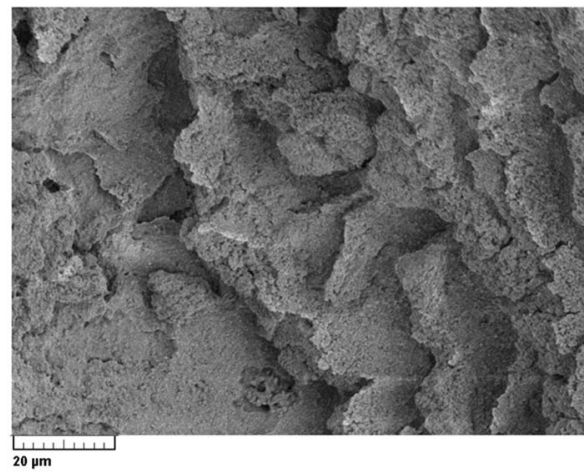

(h)

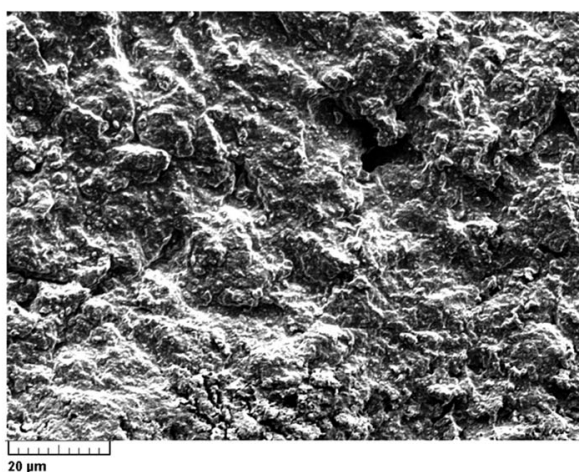

Fig. 3 Scanning electron micrographs (the left sides magnification $\times 500$ and the right sides $\times 2000$ ) of Protemp 3 Garant specimen surfaces, where a, b control; $\mathbf{c}, \mathbf{d}$ etching with $4 \%$ hydrofluoric acid; $\mathbf{e}, \mathbf{f}$ roughening with Er,Cr:YSGG laser; and $\mathbf{g}$, $\mathbf{h}$ sandblasting with $50 \mu \mathrm{m} \mathrm{Al}_{2} \mathrm{O}_{3}$

be explained by variations in compositions of the temporary materials. In terms of bis-acryl resin tested in this study, it was evident that hydrofluoric acid increased the shear bond strength. However, this effect could not be proved due to the high standard deviation in this group. The SEM images revealed the differences in the modified surfaces of the tested materials. According to the images, the surface treated with hydrofluoric acid (Figs. 3c, 4c) 
(a)

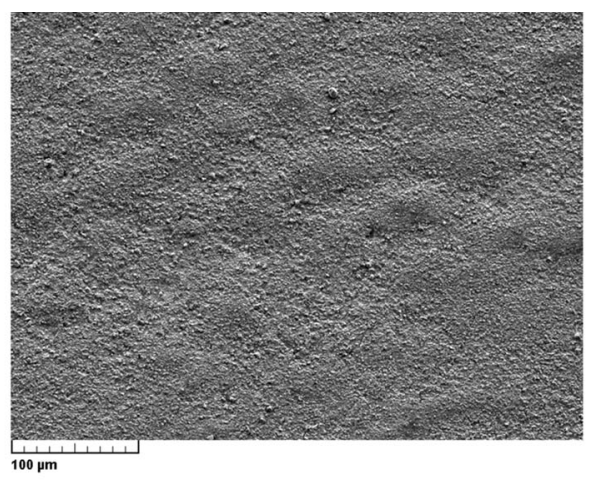

(c)

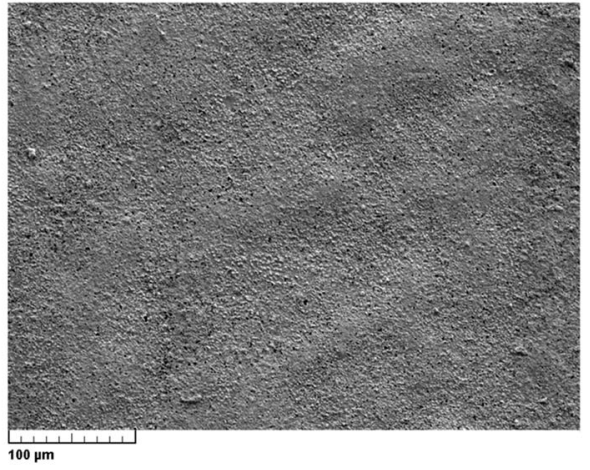

(e)

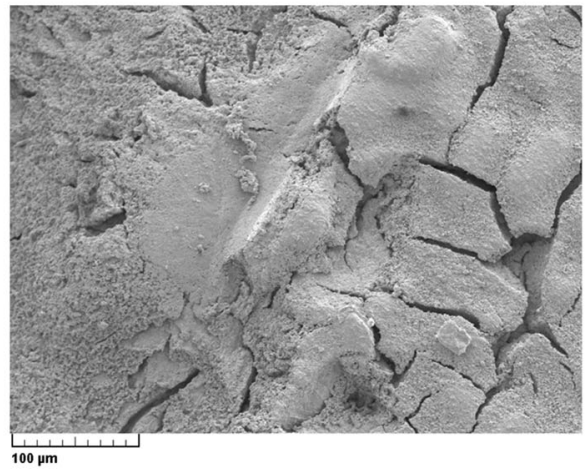

(g)

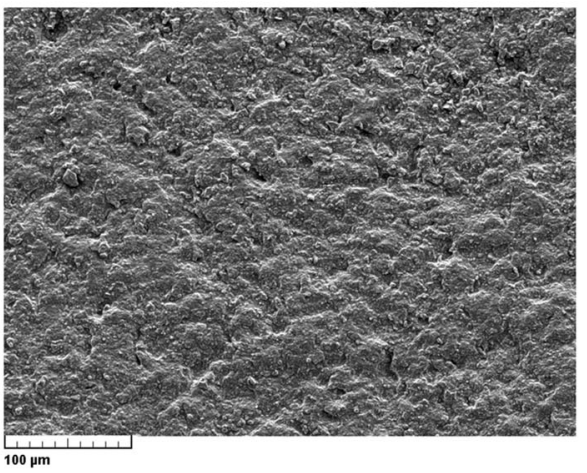

(b)

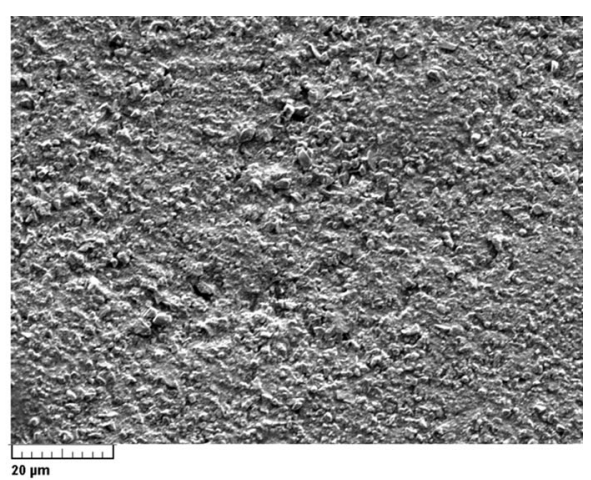

(d)

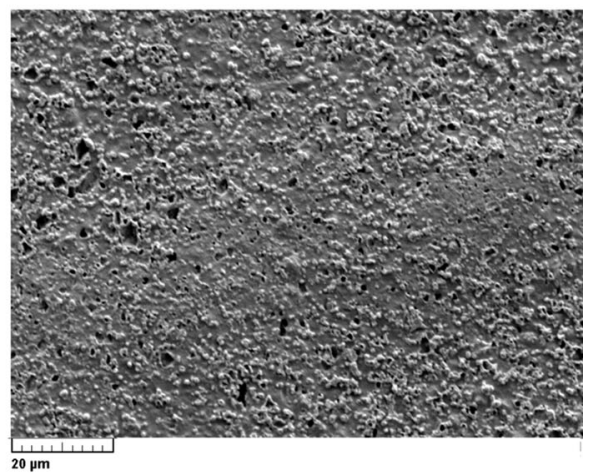

(f)

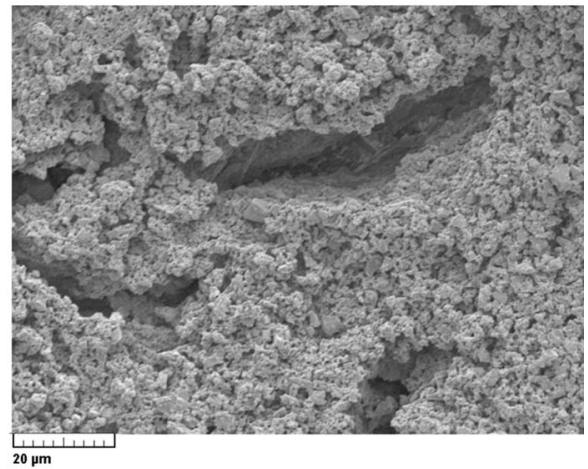

(h)

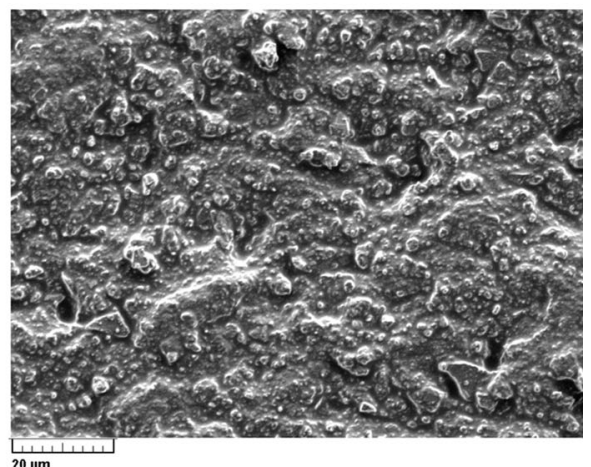

Fig. 4 Scanning electron micrographs (the left sides magnification $\times 500$ and the right sides $\times 2000$ ) of Luxatemp specimen surfaces, where a, b control; c, d etching with $4 \%$ hydrofluoric acid; e, f roughening with Er,Cr:YSGG laser; and $\mathbf{g}$, h sandblasting with $50 \mu \mathrm{m} \mathrm{Al}_{2} \mathrm{O}_{3}$

appeared to be slightly smoother than that treated with sandblasting. It suggests that the acid may have slightly eroded the bis-acryl resin surface. In addition, this surface treatment did not show the numerous surface irregularities shown by the specimens treated with laser, but no significant differences in shear bond strength between them were noted. The surface topography indicated that the lasertreated specimen has a combination of micro- and macro- 
(a)

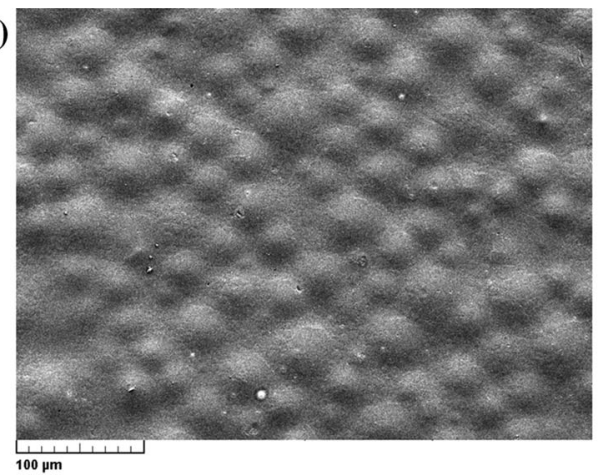

(c)

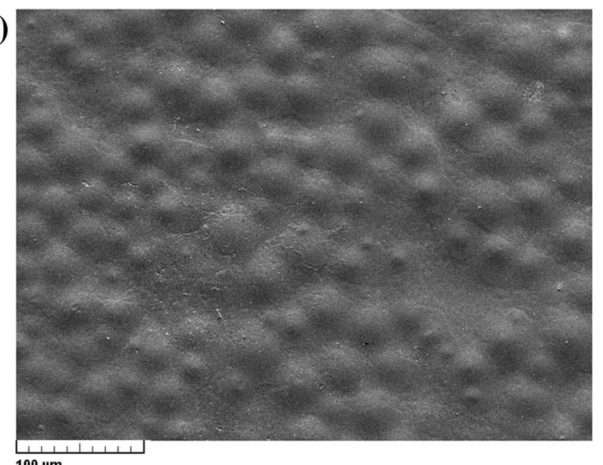

(e)

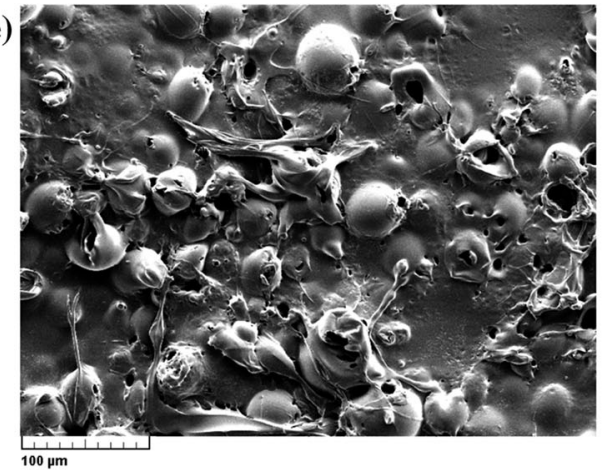

(g)

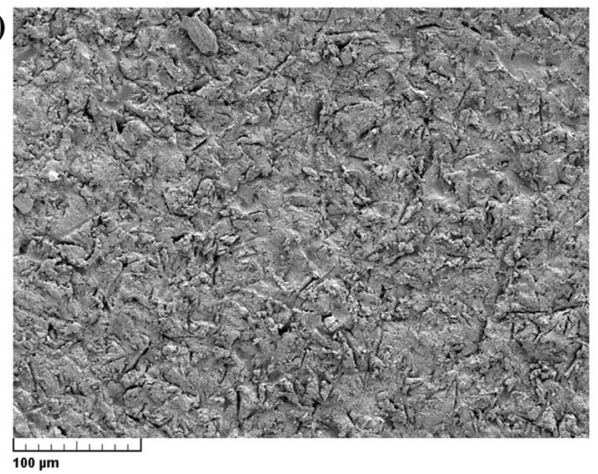

(b)

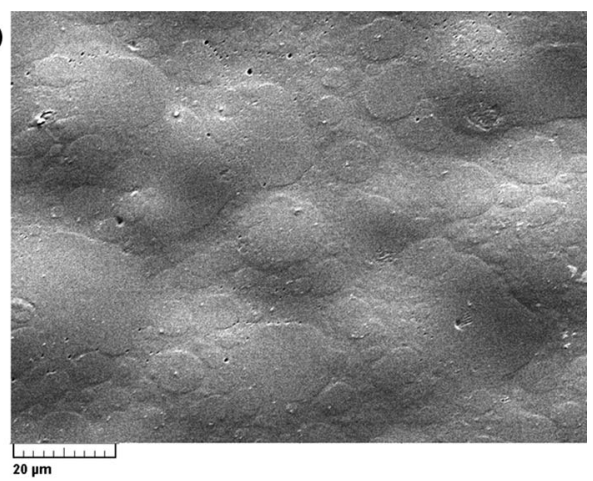

(d)

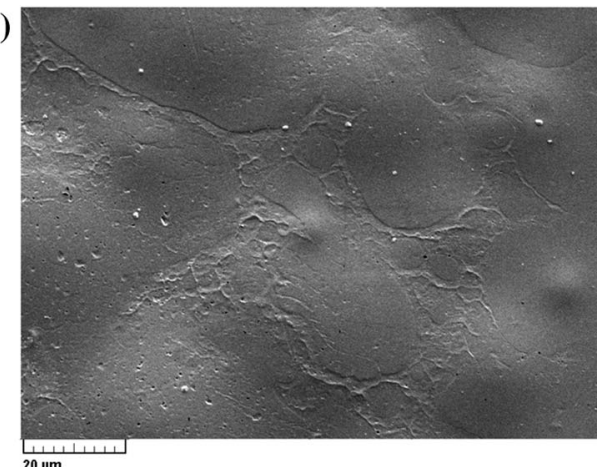

(f)

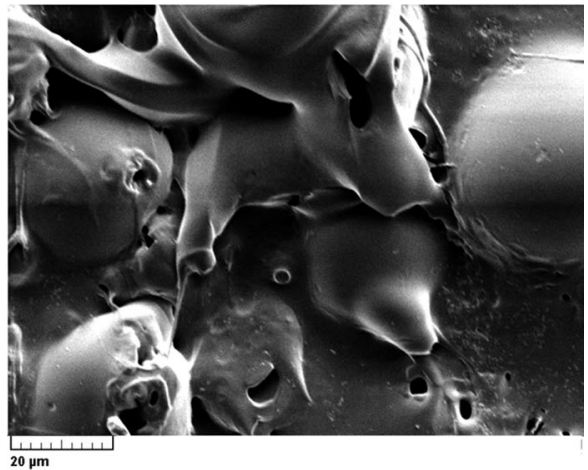

(h)

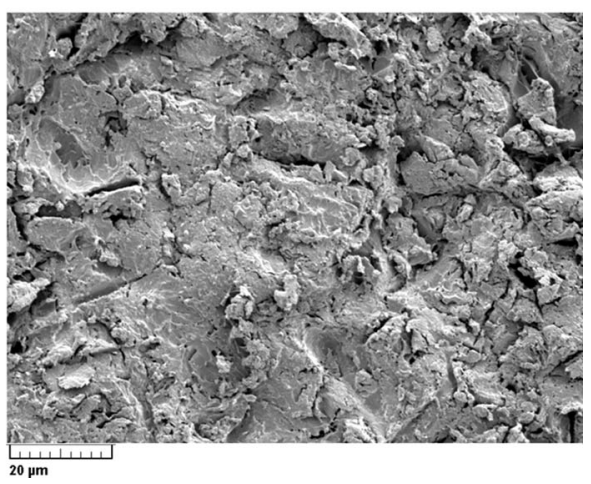

Fig. 5 Scanning electron micrographs (the left sides magnification $\times 500$ and the right sides $\times 2000$ ) of Vertex specimen surfaces, where a, b control; c, d etching with $4 \%$ hydrofluoric acid; e, f roughening with Er,Cr:YSGG laser; and $\mathbf{g}$, h sandblasting with $50 \mu \mathrm{m} \mathrm{Al}_{2} \mathrm{O}_{3}$

mechanical retention systems, but the sandblasted surface only demonstrated a micromechanical retention system and increased surface roughness.
It has been reported that the utilization of adhesive monomers significantly increases the repair bond strength in the filling composite resins [16, 28, 29]. Several possible 
(a)

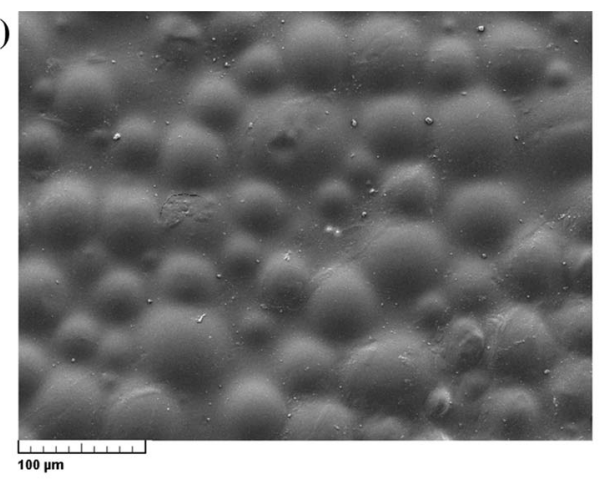

(c)

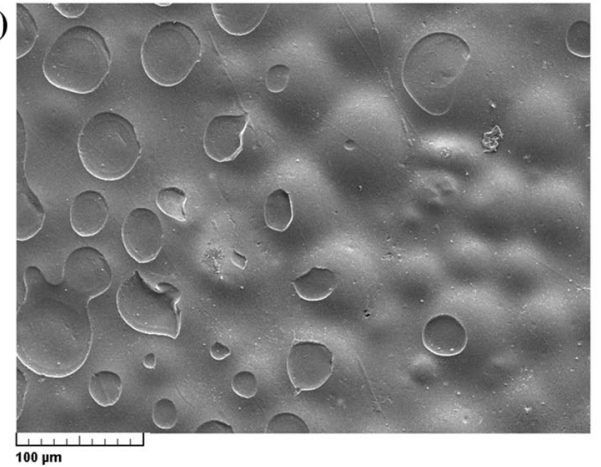

(e)

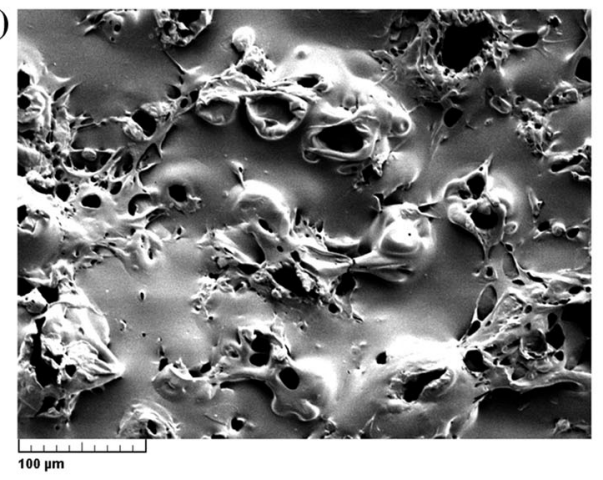

(g)

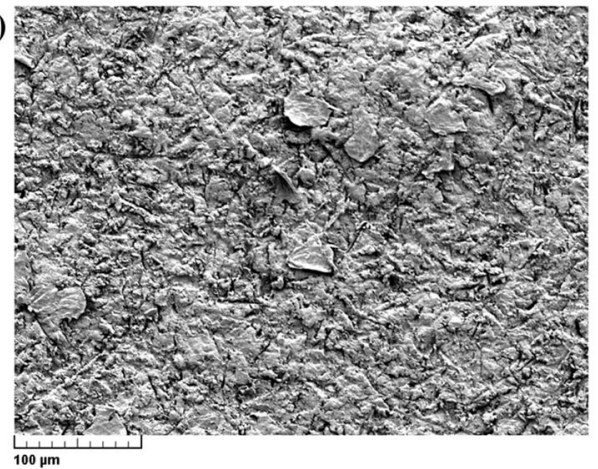

(b)

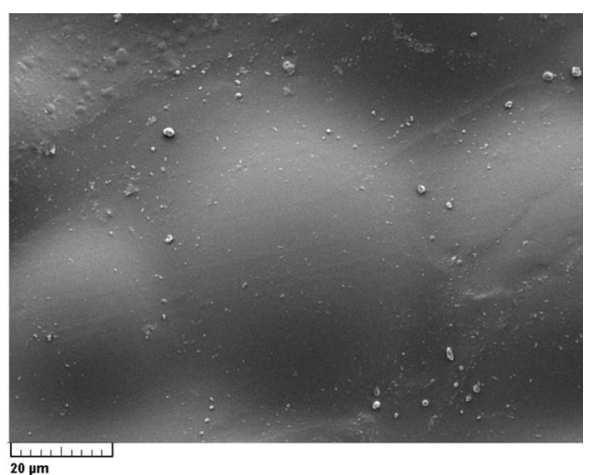

(d)

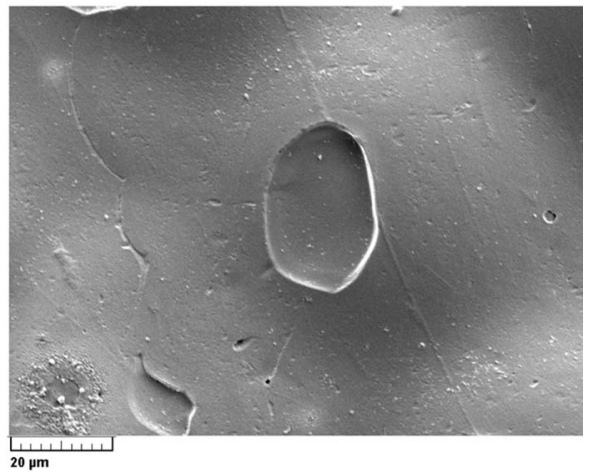

(f)

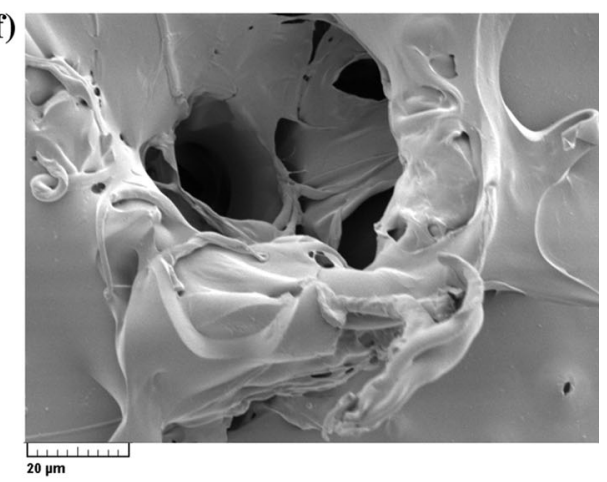

(h)

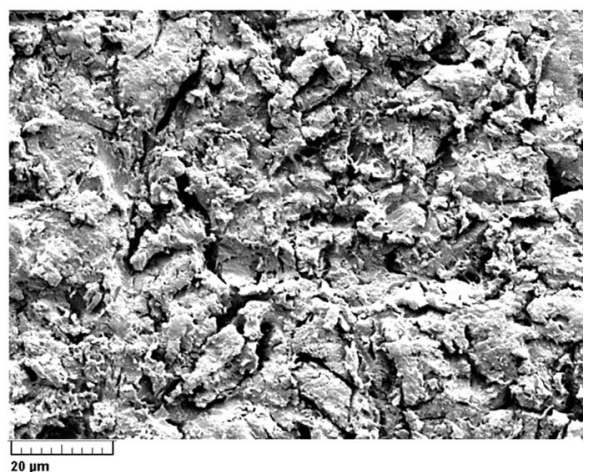

Fig. 6 Scanning electron micrographs (the left sides magnification $\times 500$ and the right sides $\times 2000$ ) of Jet specimen surfaces, where a, b control; c, d etching with $4 \%$ hydrofluoric acid; e, f roughening with Er,Cr:YSGG laser; and $\mathbf{g}$, h sandblasting with $50 \mu \mathrm{m} \mathrm{Al}_{2} \mathrm{O}_{3}$

mechanisms of the adhesive monomer during the filling composite resin repair include chemical bond formation to the surface fillers and to the matrix and micromechanical interlocking formed by infiltration of the monomer into microcracks in the matrix [30]. Many adhesive monomers consist of chloro-phosphate esters of bis-GMA resin. Since the phosphate groups are polar, they may play a role in the affinity of inorganic filler particles by bonding to silane and 

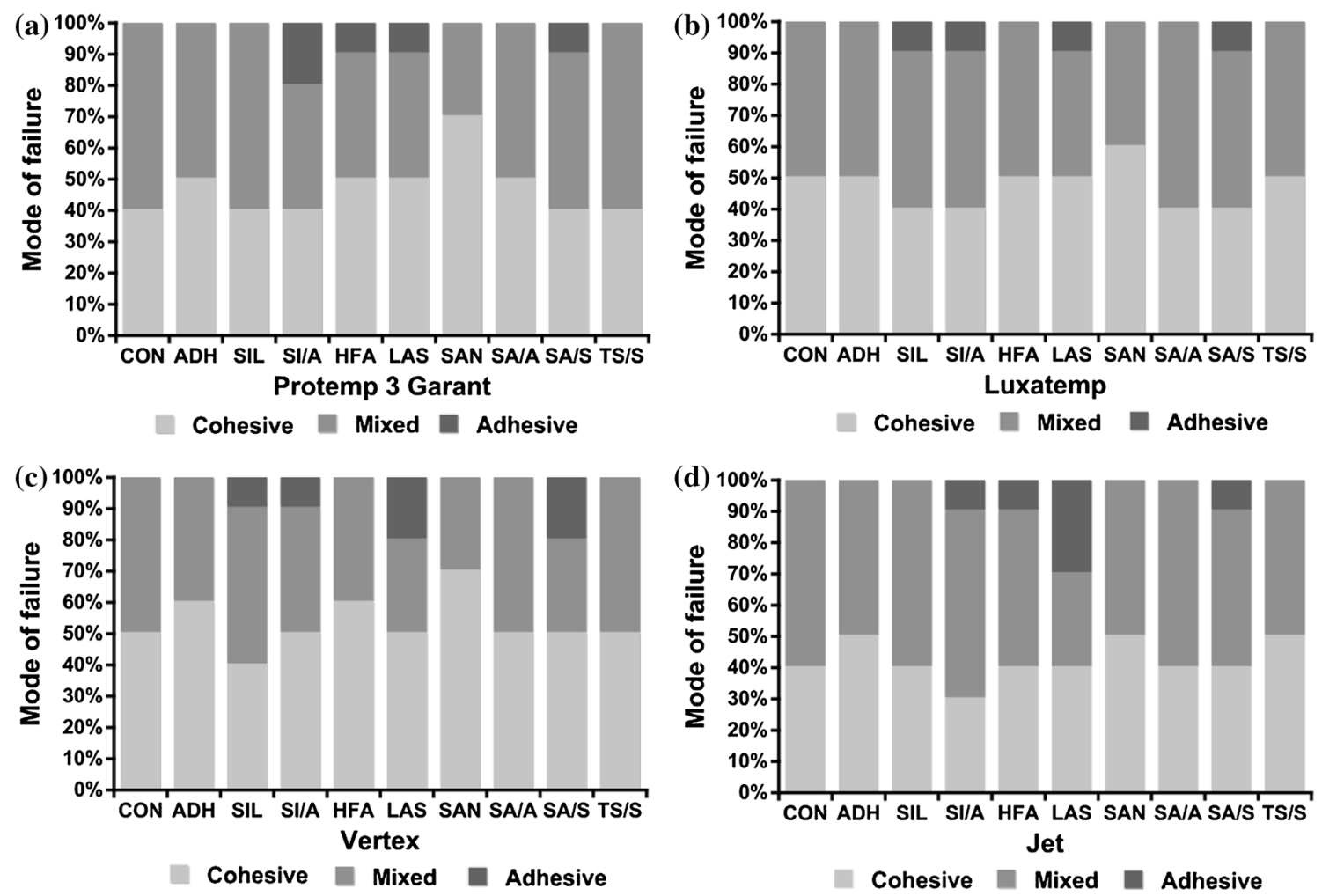

Fig. 7 Failure mode distribution of the experimental and control groups. Group codes: $C O N$ control, $A D H$ adhesive, SIL silane, SI/A silane + adhesive, HFA hydrofluoric acid, $L A S$ laser, SAN

sandblasting, $S A / A$ sandblasting + adhesive, $S A / S$ sandblasting + silane, $T S / S$ tribochemical silica coating + silane

hydrogen. This may form covalent bond to the unreacted methacrylate groups on the matrix [28]. In addition, the adhesive monomers enable the achievement of better wetting of the surface [25]. A solvent and a surfactant are often added, and the wetting properties of the adhesive monomers are increased by their low viscosity [19, 28, 31]. Adhesives promote penetration of solvent systems and of monomers into the composite surface, depending on the degree of hydration and the chemical affinity of materials, and create a non-polymerized oxygen inhibition layer that could ultimately promote adhesion of new composites [32, 33]. However, the study of Hagge et al. [34] showed that the shear bond strength values of the flowable composite resin were significantly higher in surface treatment with sandblasting alone than with the combination of sandblasting and adhesive monomer. The results of the present study correspond well with those of the earlier studies in the composite resin. The current study showed that the use of the adhesive monomer did not enhance the repair bond strengths of all tested temporary resins except for Vertex.

When the material has no specific groups to bond to the silane coupling agent or when little filler remains on the surface, the effect of silane could be useless [25]. The surface could be treated with tribochemical silica coating to achieve a chemical bonding with the silane. Through this

treatment, it is possible to deposit a mixture of silica particles and alumina on the surface [35]. These particles could form covalent bonds through its hydroxyl groups with hydrolyzed silanol groups in the silane. This makes the surface more reactive to the methacrylate groups of the resin $[25,36]$. Silane coupling agent improves the wettability of the filler and adhesive monomer that facilitates their infiltration into the irregularities created by sandblasting $[25,36]$. However, in the present study, silanization of specimens after tribochemical silica coating or sandblasting did not increase the shear bond strength significantly. The failure of silane coupling agents to increase the shear bond strength may propose that mechanical retention is the single most important factor contributing to bond strength. The repair procedure should not alter the original color of the temporary restorations. Moreover, the procedure needs to be easy, rapid, and inexpensive to perform. In the present study, roughening the surface of bis-acryl resin by sandblasting showed a greater improvement on the repair strength than using the chemical treatment. Thus, it appears that the application of chemical agent is unnecessary for repairing temporary restorations.

The values of strengths obtained in the present study seem to be higher than those in clinical situations because the repairs were carried out only a few hours after 
polymerization of the original temporary materials. Furthermore, the repaired surface was stored largely untouched until the surface modification procedures. Bond strength between the original material and newly added resin is dependent on unreacted $\mathrm{C}=\mathrm{C}$ double bonds [25]. The resins often have incomplete $\mathrm{C}=\mathrm{C}$ double-bond conversion after being polymerized [37]. As the material ages, more cross-linking decreases the capability of fresh monomer to infiltrate into the matrix, and fewer and fewer unreacted $\mathrm{C}=\mathrm{C}$ double bonds remain [38].

The results of in vitro testing cannot be postulated in the clinical situation, as the design of the present study did not consider factors in the oral environment, such as dynamic forces of mastication or fatigue loading. The repaired surface area used in this study was about $7 \mathrm{~mm}^{2}\left(1.5^{2} \pi\right)$, but fractured surface area of clinically used temporary restorations is usually of a smaller size. It should be noted that this was a comparative study where all variables were controlled except for the surface treatment. Hence, it should be kept in mind that the shear bond strength is only one of many behaviors in response to a particular stress and that strength is just one property of temporary crown and FDP materials. In addition, the present study design offered no data on the long-term stability of the repaired specimens. Further investigations are necessary to evaluate the effect of the thermal cycling on the repair bond strength of temporary crown and FDP materials. Moreover, it is necessary to determine the repair bond strength after long-term use of the materials. Finally, the influence of changing the application condition of sandblasting needs further investigation.

\section{Conclusions}

The surface treatment of bis-acryl resins with sandblasting seems to be promising for the improvement of repair bond strength.

\section{Compliance with ethical standards}

Conflict of Interest The authors declare that they have no potential conflict of interest to this work.

Open Access This article is distributed under the terms of the Creative Commons Attribution 4.0 International License (http://creati vecommons.org/licenses/by/4.0/), which permits unrestricted use, distribution, and reproduction in any medium, provided you give appropriate credit to the original author(s) and the source, provide a link to the Creative Commons license, and indicate if changes were made.

\section{References}

1. Gratton DG, Aquilino SA (2004) Interim restorations. Dent Clin North Am 48(vii):487-497. doi:10.1016/j.cden.2003.12.007
2. Gergauff AG, Holloway JA (2000) Provisional restorations. In: Rosenstiel SF, Land MF, Fujimoto J (eds) Contemporary fixed prosthodontics, 3rd edn. Mosby, St. Louis, pp 380-416

3. el-Ebrashi MK, Craig RG, Peyton FA (1970) Experimental stress analysis of dental restorations. VII. Structural design and stress analysis of fixed partial dentures. J Prosthet Dent 23:177-186

4. Kim SH, Watts DC (2007) In vitro study of edge-strength of provisional polymer-based crown and fixed partial denture materials. Dent Mater 23:1570-1573. doi:10.1016/j.dental.2007. 06.023

5. da Costa TR, Serrano AM, Atman AP, Loguercio AD, Reis A (2012) Durability of composite repair using different surface treatments. J Dent 40:513-521. doi:10.1016/j.jdent.2012.03.001

6. Hickel R, Brushaver K, Ilie N (2013) Repair of restorationscriteria for decision making and clinical recommendations. Dent Mater 29:28-50. doi:10.1016/j.dental.2012.07.006

7. Ozcan M, Corazza PH, Marocho SM, Barbosa SH, Bottino MA (2013) Repair bond strength of microhybrid, nanohybrid and nanofilled resin composites: effect of substrate resin type, surface conditioning and ageing. Clin Oral Investig 17:1751-1758. doi:10.1007/s00784-012-0863-5

8. Baur V, Ilie N (2013) Repair of dental resin-based composites. Clin Oral Investig 17:601-608. doi:10.1007/s00784-012-0722-4

9. Bacchi A, Consani RL, Sinhoreti MA, Feitosa VP, Cavalcante LM, Pfeifer CS, Schneider LF (2013) Repair bond strength in aged methacrylate- and silorane-based composites. J Adhes Dent 15:447-452. doi:10.3290/j.jad.a29590

10. El-Askary FS, El-Banna AH, van Noort R (2012) Immediate vs delayed repair bond strength of a nanohybrid resin composite. J Adhes Dent 14:265-274. doi:10.3290/j.jad.a22716

11. Melo MA, Moyses MR, Santos SG, Alcantara CE, Ribeiro JC (2011) Effects of different surface treatments and accelerated artificial aging on the bond strength of composite resin repairs. Braz Oral Res 25:485-491

12. Koumjian JH, Nimmo A (1990) Evaluation of fracture resistance of resins used for provisional restorations. J Prosthet Dent 64:654-657

13. Hammond BD, Cooper JR 3rd, Lazarchik DA (2009) Predictable repair of provisional restorations. J Esthet Restor Dent 21:19-24. doi:10.1111/j.1708-8240.2008.00225.x discussion 25

14. Chen HL, Lai YL, Chou IC, Hu CJ, Lee SY (2008) Shear bond strength of provisional restoration materials repaired with lightcured resins. Oper Dent 33:508-515. doi:10.2341/07-130

15. Patras M, Naka O, Doukoudakis S, Pissiotis A (2012) Management of provisional restorations' deficiencies: a literature review. J Esthet Restor Dent 24:26-38. doi:10.1111/j.1708-8240.2011. 00467.x

16. Turner CW, Meiers JC (1993) Repair of an aged, contaminated indirect composite resin with a direct, visible-light-cured composite resin. Oper Dent 18:187-194

17. Kimyai S, Oskoee SS, Mohammadi N, Rikhtegaran S, Bahari M, Oskoee PA, Vahedpour H (2015) Effect of different mechanical and chemical surface treatments on the repaired bond strength of an indirect composite resin. Lasers Med Sci 30:653-659. doi:10. 1007/s10103-013-1391-5

18. Eliades GC, Caputo AA (1989) The strength of layering technique in visible light-cured composites. J Prosthet Dent 61:31-38

19. Eli I, Liberman R, Levi N, Haspel Y (1988) Bond strength of joined posterior light-cured composites: comparison of surface treatments. J Prosthet Dent 60:185-189

20. Pounder B, Gregory WA, Powers JM (1987) Bond strengths of repaired composite resins. Oper Dent 12:127-131

21. Gregory WA, Pounder B, Bakus E (1990) Bond strengths of chemically dissimilar repaired composite resins. J Prosthet Dent 64:664-668 
22. Mohammadi N, Savadi Oskoee S, Abed Kahnamoui M, Bahari M, Kimyai S, Rikhtegaran S (2013) Effect of Er, Cr:YSGG pretreatment on bond strength of fiber posts to root canal dentin using a self-adhesive resin cement. Lasers Med Sci 28:65-69. doi:10.1007/s10103-012-1063-x

23. Perussi LR, Pavone C, de Oliveira GJ, Cerri PS, Marcantonio RA (2012) Effects of the Er, Cr:YSGG laser on bone and soft tissue in a rat model. Lasers Med Sci 27:95-102. doi:10.1007/s10103011-0920-3

24. Swift EJ Jr, LeValley BD, Boyer DB (1992) Evaluation of new methods for composite repair. Dent Mater 8:362-365

25. Ozcan M, Alander P, Vallittu PK, Huysmans MC, Kalk W (2005) Effect of three surface conditioning methods to improve bond strength of particulate filler resin composites. J Mater Sci Mater Med 16:21-27. doi:10.1007/s10856-005-6442-4

26. Bouschlicher MR, Reinhardt JW, Vargas MA (1997) Surface treatment techniques for resin composite repair. Am J Dent 10:279-283

27. Kula K, Nelson S, Kula T, Thompson V (1986) In vitro effect of acidulated phosphate fluoride gel on the surface of composites with different filler particles. J Prosthet Dent 56:161-169

28. Shahdad SA, Kennedy JG (1998) Bond strength of repaired anterior composite resins: an in vitro study. J Dent 26:685-694

29. Oztas N, Alacam A, Bardakcy Y (2003) The effect of air abrasion with two new bonding agents on composite repair. Oper Dent 28:149-154

30. Brosh T, Pilo R, Bichacho N, Blutstein R (1997) Effect of combinations of surface treatments and bonding agents on the bond strength of repaired composites. J Prosthet Dent 77:122-126
31. Puckett AD, Holder R, O'Hara JW (1991) Strength of posterior composite repairs using different composite/bonding agent combinations. Oper Dent 16:136-140

32. Teixeira EC, Bayne SC, Thompson JY, Ritter AV, Swift EJ (2005) Shear bond strength of self-etching bonding systems in combination with various composites used for repairing aged composites. J Adhes Dent 7:159-164

33. Lastumaki TM, Kallio TT, Vallittu PK (2002) The bond strength of light-curing composite resin to finally polymerized and aged glass fiber-reinforced composite substrate. Biomaterials 23:4533-4539

34. Hagge MS, Lindemuth JS, Jones AG (2002) Shear bond strength of bis-acryl composite provisional material repaired with flowable composite. J Esthet Restor Dent 14:47-52

35. Ozcan M (2002) The use of chairside silica coating for different dental applications: a clinical report. J Prosthet Dent 87:469-472

36. Ozcan M, Barbosa SH, Melo RM, Galhano GA, Bottino MA (2007) Effect of surface conditioning methods on the microtensile bond strength of resin composite to composite after aging conditions. Dent Mater 23:1276-1282. doi:10.1016/j.dental.2006.11. 007

37. Floyd CJ, Dickens SH (2006) Network structure of Bis-GMAand UDMA-based resin systems. Dent Mater 22:1143-1149. doi:10.1016/j.dental.2005.10.009

38. Chay SH, Wong SL, Mohamed N, Chia A, Yap AU (2007) Effects of surface treatment and aging on the bond strength of orthodontic brackets to provisional materials. Am J Orthod Dentofacial Orthop 132:577.e7-577.e11. doi:10.1016/j.ajodo. 2004.01.024 